\title{
Ion chromatography in the liqueurs and spirits quality control
}

\author{
Irina Abramova ${ }^{1,{ }^{*}}$, Marina Medrish ${ }^{1}$, Vera Savel'yeva $^{1}$, Aleksandra Romanova $^{1}$, and Darya \\ Gavrilova $^{1}$ \\ ${ }^{1}$ All-Russian research Institute of food biotechnology branch of the FRS of nutrition, biotechnology \\ and food safety, 4-b, Samokatnaya str., Moscow, 111033, Russia
}

\begin{abstract}
In the presented work, the ionic composition of liqueurs and spirits from different manufacturers was investigated. It was found that the ionic composition of studied samples is represented mainly by cations of sodium, potassium, calcium and magnesium and anions of chlorides, nitrates, phosphates and sulfates, mass concentrations vary within wide limits, which is explained by the rich microelement composition of receptive components, the specifics of alcoholic beverages and the peculiarities of water treatment of various manufacturers. It was revealed that one of the main reasons for the deterioration in the quality of liqueurs and spirits was the increased content of calcium and magnesium. In some samples, on the contrary, the relationship between the cation-anion composition and precipitation was excluded. Thus, the ion chromatography method is an indispensable modern analytical tool in the finished products quality control. Its use allows you to quickly identify and eliminate the causes of precipitation during storage, thereby increasing the efficiency of technochemical quality control of alcoholic beverages.
\end{abstract}

\section{Introduction}

Liqueurs and spirits are alcoholic beverages, which are mixtures of various alcoholized juices, fruit infusions, infusions and aromatic alcohols obtained by processing fruit and berry plant materials with the addition of sugar syrup, essential oils, grape wines, cognac, citric acid and other food additives, as well as alcohol and water. Depending on the raw materials, manufacturing technology, chemical composition, liqueurs and spirits are divided into sweet (strong liqueurs, dessert liqueurs, creams, fruit liqueurs, sweet tinctures, dessert drinks, punches, aperitifs) and bitters (balsams, bitters).

The quality of liqueurs and spirits depends on many parameters. For the production of liqueurs and spirits, plant materials, which have a high biological value in sources of vitamins and mineral elements, essential oils, acids and carbohydrates (various berries, herbs and roots - taiga and middle strips, pine and other nuts, cereals, fruits, fruits and vegetables in the form of alcoholic infusions, aromatic alcohols and extracts) are widely

* Corresponding author: i-abramova@mail.ru 
used [1]. This leads to a complex chemical composition of the finished product and requires an integrated approach to quality control. The macroelements contained in plant materials include potassium, sodium, calcium, magnesium, phosphorus, iron and chlorine; microelements - manganese, copper, zinc, iodine, cobalt, molybdenum, etc. The content of macro- and microelements in plants varies depending on their type [2].

The ionic composition of process water has a great influence on the quality and stability of alcoholic beverages. It is known that calcium ions determine the fullness of the taste, calcium bicarbonates soften the taste and reduce the pungency of strong alcoholic beverages. At the same time, the calcium content in process water is strictly regulated, since the increased content of $\mathrm{CaCO}_{3}$ is one of the reasons for sedimentation. Ions can react with pectin and tannins of fruits and berries infusions used in the manufacture of liqueurs and spirits, forming insoluble compounds precipitated out [3].

Manufacturing equipment can be a potential source of alkaline earth metal ions. As a result of research by scientists [4], it was revealed that from filter cartons, as well as diatomite and asbestos used in filtration, microelements, which have a catalytic effect on sediment formation in alcoholic beverages bases and finished products are washed out. The largest amount is washed out by calcium cations, then silicon, and then iron. Iron and aluminum form complexes with amino acids, mono- and disaccharides, phenolic compounds. Under certain environmental conditions, calcium forms complexes with pectin substances that have passed into aqueous-alcoholic solutions upon infusion.

Glass containers are another potential source of metal ions in alcoholic beverages. With a deviation from the technological parameters, soluble components can form on the surface of the glass of the bottle, which then pass into an alcoholic drink, as a result of which turbidity is formed in it. In the process of storing a bottle with an alcoholic drink, the glass surface is disturbed, as a result of which the drink is enriched with sodium and calcium cations. During storage of glass containers, irreversible processes take place in the structure of the glass bottle, which lead to increased leaching of the glass [5].

It is not only ions that can cause precipitation in alcoholic beverages. Process water always contains dissolved and colloidal silicic acid. At $\mathrm{pH}$ values $>7$, in the presence of calcium ions, the dissolved undissociated acid precipitates, forming silicates that are poorly soluble in a water-alcohol medium. The reaction proceeds slowly, which can lead to the formation of precipitates during long-term storage [6,7].

To determine the content of cations and anions in alcoholic beverages, the method of ion chromatography with conductometric detection and chemical suppression of background electrical conductivity or without is used. This method makes it possible to detect ions of lithium, sodium, ammonium, potassium, calcium, magnesium, strontium, barium, fluorides, chlorides, nitrites, phosphates, sulfates, etc. [8-12] Polish scientists have developed an express method [13] for determining organic and inorganic anions in vodka and rum samples, which within 35 minutes allows you to determine the main organic and inorganic anions contained in alcoholic beverages.

American scientists [14] studied the content of cations and anions $\left(\mathrm{Na}^{+}, \mathrm{NH}_{4}^{+}, \mathrm{K}^{+}, \mathrm{Ca}^{2+}\right.$, $\left.\mathrm{Mg}^{2+}, \mathrm{PO}_{4}{ }^{3-}, \mathrm{SO}_{4}{ }^{2-}, \mathrm{Cl}^{-}\right)$in beer, wine, fruit juices and other drinks. The authors found that all studied juices contained potassium and magnesium ions, chlorides. Most of the samples contained sodium and calcium cations, phosphate and sulfate anions.

The ionic composition of liqueurs and spirits is strictly tied to a specific production and can serve as a marker for its identification [15].

The content of microelements in liqueurs and spirits largely determines their quality and safety, and also affects their stability during storage.

Most of foreign studies of liqueurs and spirits are devoted to the study of the component composition (volatile aromatic compounds) [16] and trace elements [17] in order to control their quality and safety, as well as to study their antioxidant activity $[18,19]$. 
In the VNIIPBT - branch of the Federal Research Center "Nutrition and Biotechnology", methods were developed for the determination of cations and anions in vodkas and special vodkas by ion chromatography method, studies were carried out to determine the effect of the cationic and anionic composition of vodkas on their stability during storage [7]. The purpose of our work was to study the ionic composition of liqueurs and spirits using the developed methods as one of the possible reasons for the deterioration of their quality.

\section{Materials and methods}

\subsection{Apparatus}

The ECO IC System and 761 Compact IC System from Metrohm (Switzerland) with a conductometric detector was used. Anion separations were investigated with the use of two different chromatographic columns, Metrosep A Supp $5(150 / 4.0 \mathrm{~mm})$ (eluent - a solution of a mixture of $3.2 \mathrm{mmol} / \mathrm{dm}^{3} \mathrm{Na}_{2} \mathrm{CO}_{3}$ and $1.0 \mathrm{mmol} / \mathrm{dm}^{3} \mathrm{NaHCO}_{3}$; eluent flow rate 0.7 $\mathrm{cm}^{3} / \mathrm{min}$.) and Metrosep A Supp $16(150 / 4.0 \mathrm{~mm})\left(5 \mathrm{mmol} / 1 \mathrm{Na}_{2} \mathrm{CO}_{3}\right.$ and $0.75 \mathrm{mmol} / \mathrm{dm}^{3}$ $\mathrm{NaOH}$; eluent flow rate $0.8 \mathrm{~cm}^{3} / \mathrm{min}$ ) from Metrohm, Switzerland. Cation separations were investigated with the use of two different chromatographic columns Metrosep C 2 (150/4.0 $\mathrm{mm}$ ) (eluent - a solution of $2.0 \mathrm{mmol} / \mathrm{dm}^{3} \mathrm{HNO}_{3}$; eluent flow rate $1.0 \mathrm{~cm}^{3} / \mathrm{min}$ ) and Metrosep C 4 (150/4.0 mm) (eluent: $1.7 \mathrm{mmol} / \mathrm{dm}^{3} \mathrm{HNO}_{3}$ and $0.7 \mathrm{mmol} / \mathrm{dm}^{3}$ dipicolinic acid; eluent flow rate $0.9 \mathrm{~cm}^{3} / \mathrm{min}$ ) from Metrohm, Switzerland. Data acquisition and evaluation of chromatograms were carried out with the MagIC Net 2.3 Metrodata (Metrohm) software.

Filters of $0.45 \mu \mathrm{m}$ pore size were used for sample filtration.

A pH meter $827 \mathrm{pH}$ lab Metrohm Swissmade was used to measure $\mathrm{pH}$.

\subsection{Reagents}

All reagents used were of analytical grade. Water (a specific resistance $>18.2 \mathrm{M} \Omega \mathrm{cm}$ ) was used in all experiments.

Standard solutions of cations and anions were prepared from state standard reference sample and containing $1000 \mathrm{mg} / \mathrm{L}$ relative error no more than $1 \%$ at $=0.95$ of each cation and anion.

\subsection{Analytical Procedure}

Each sample of liqueurs and spirits was diluted with deionized water 1:10 and submitted to ion chromatographic analysis after triple filtration through a $0.45-\mu \mathrm{m}$ filter.

The qualitative composition of the sediments was determined by ion chromatography.

\subsection{Commercial samples for analysis}

Two different spirit drink groups were analyzed: bitter tinctures (36 samples), sweet and semi-sweet tinctures (13 samples). In our study, we used industrial samples of alcoholic beverages containing inclusions, turbidity and precipitation, and samples of the same name, that comply with normative documentation in appearance. Besides, an assessment was made of the quality of the bottles by the parameter of water resistance (GOST 13905-2005).

Sample list is presented in Table 1 , where * denotes samples with sediment. 
Table 1. Analyzed samples list.

\begin{tabular}{|l|c|c|}
\hline \multirow{2}{*}{ Raw material } & Bitter tinctures & $\begin{array}{c}\text { Sweet and semi-sweet } \\
\text { tinctures }\end{array}$ \\
\cline { 2 - 3 } & \multicolumn{2}{|c|}{ Sample number } \\
\hline $\begin{array}{l}\text { Aromatic raw material } \\
\text { (herbs, spices) }\end{array}$ & $1-4,5^{*}, 6,10,13,33$ & - \\
\hline $\begin{array}{l}\text { Fruit raw material (hot red } \\
\text { pepper, berries, roots, nuts) }\end{array}$ & $\begin{array}{c}15-22,23^{*}, 24,25^{*}, 34-36, \\
39,40^{*}, 41,42^{*}\end{array}$ & $26,27^{*} 37,38^{*}$ \\
\hline $\begin{array}{l}\text { With the addition of cognac and } \\
\text { / or wine materials }\end{array}$ & $8,9,11,12,17$ & $29,30-32,43,44^{*}$ \\
\hline $\begin{array}{l}\text { With the addition of colorants } \\
\text { and flavors }\end{array}$ & 14 & $28,45,46^{*}$ \\
\hline
\end{tabular}

\section{Results and discussion}

The ionic composition of studied samples is mainly represented by sodium, potassium, calcium and magnesium cations and anions of chlorides, nitrates, phosphates and sulfates. The mass concentrations of ions fluctuate within wide limits, which is explained by the rich trace element composition of plant components, the specificity of formulations and the peculiarity of water treatment from different manufacturers. The ranges of mass concentrations of the studied ions in bitter tinctures differ from sweet ones in their lower content. At the same time, the ranges of mass concentrations of the studied ions differ depending on the type of raw material used. The lowest concentrations were in the samples prepared with the addition of colorants and flavors. And their greatest content was in samples made on the basis of wine materials and cognac. Ammonium ions were detected in only ten samples $(27,29,31,33,37-40,42,43)$, the mass concentration range was $0.2-8.7$ $\mathrm{mg} / \mathrm{dm}^{3}$. Nitrates were in an even smaller range of $0.1-4.1 \mathrm{mg} / \mathrm{dm}^{3}$ (due to their low concentrations, both ions are not represented in the general diagrams). The results are presented graphically in Fig. 1-4.

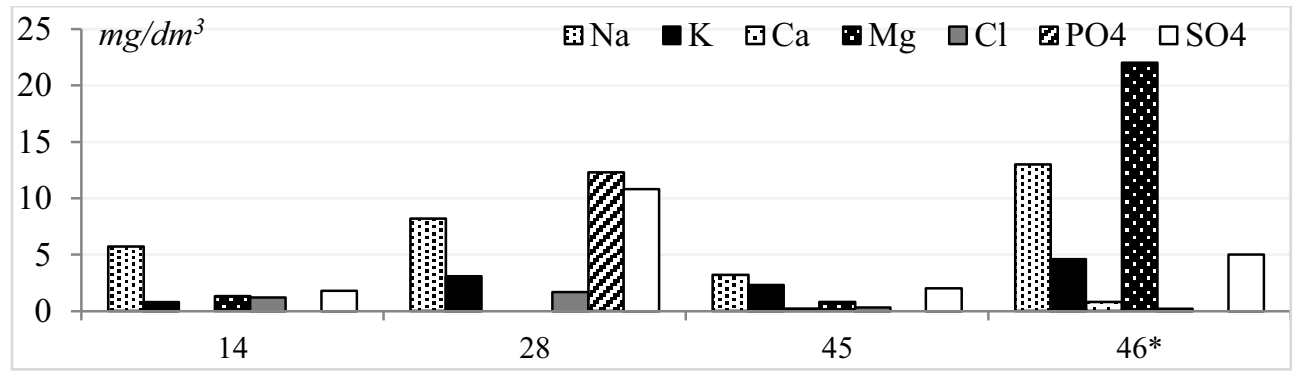

Fig. 1. Ionic composition of liqeurs and spirits samples with the addition of colorants and flavors.

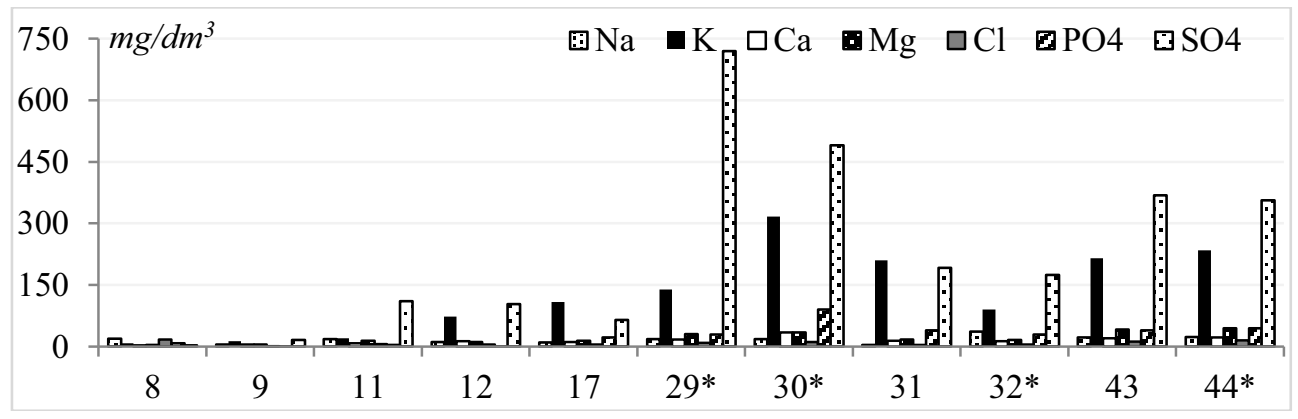


Fig. 2. Ionic composition of liqeurs and spirits samples with the addition of cognac and/or wine materials.

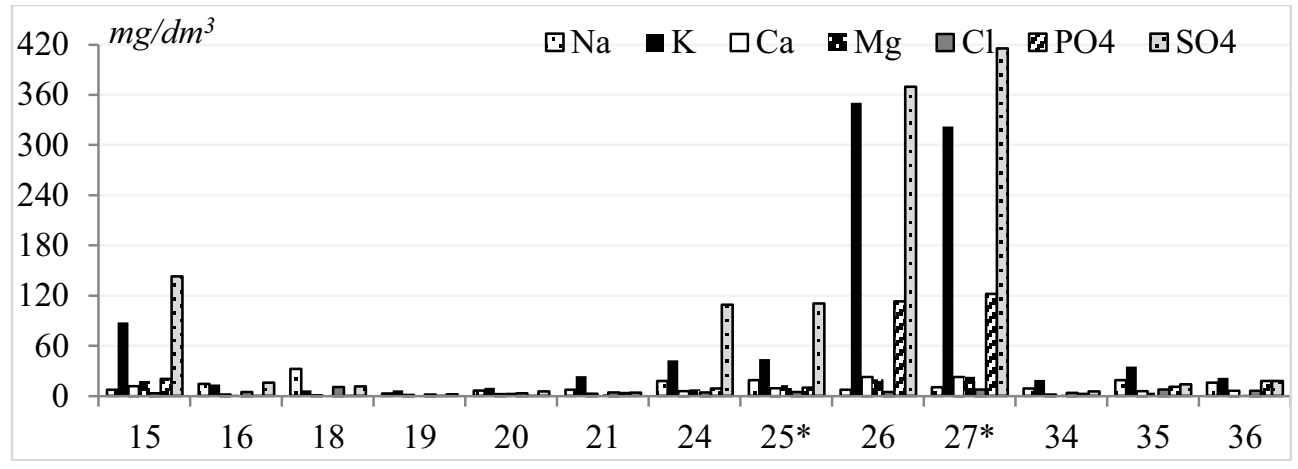

Fig. 3. Ionic composition of liqeurs and spirits samples made from fruit raw material

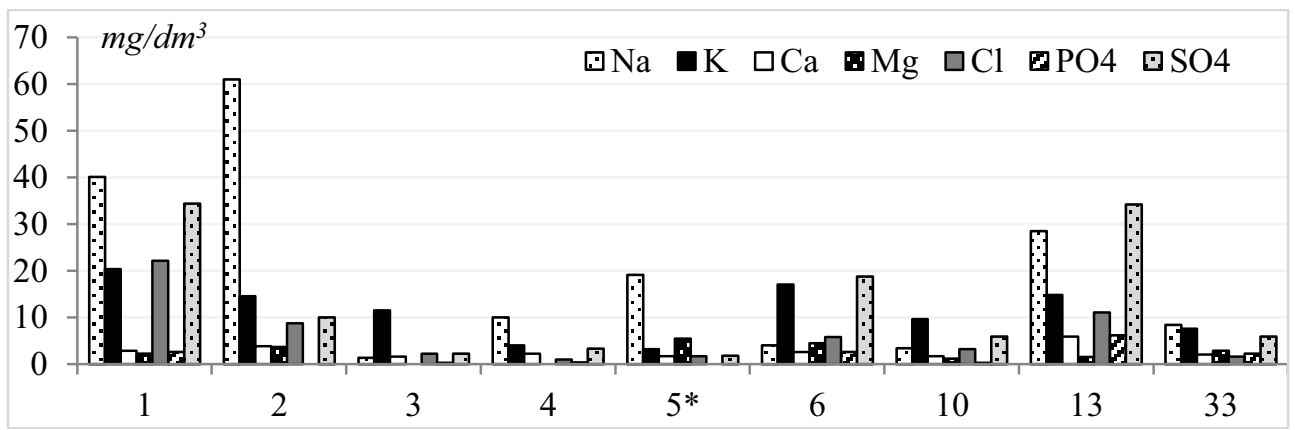

Fig. 4. Ionic composition of liqeurs and spirits samples made from aromatic raw material

In samples from natural plant materials, there are significantly more potassium ions than in samples made using dyes and flavors $(14,28,45,46)$ [20]. At the same time, the highest content of potassium ions is observed in the samples, in the manufacture of which cognac or wine materials were used. $(12,17,29-32,43,44)$.

Analysis of the results obtained showed that one of the reasons for the deterioration in quality was the increased content of calcium and magnesium ions. It is known that an increased content of hardness salts promotes sedimentation. In several samples of bitters with sediment, the mass concentration of calcium and magnesium ions is lower than in the same samples without sediment (Fig. 5, 6). This is due to the fact that the salts of these ions precipitated.

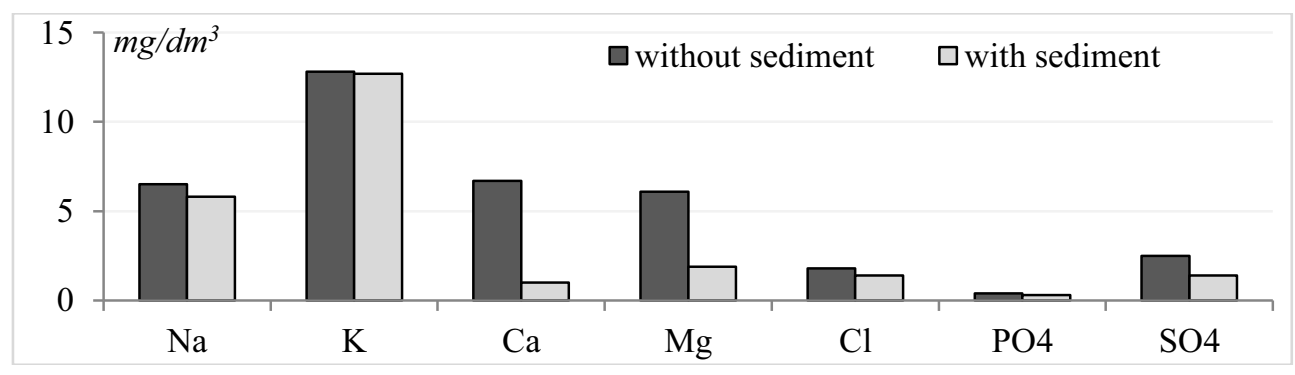

Fig. 5. Comparative diagram of the quantitative content of the cationic and anionic composition of the Bitter tincture sample "Russian crown with pepperon honey" with sediment (sample 40) and without (sample 39), $\mathrm{mg} / \mathrm{dm}^{3}$ 


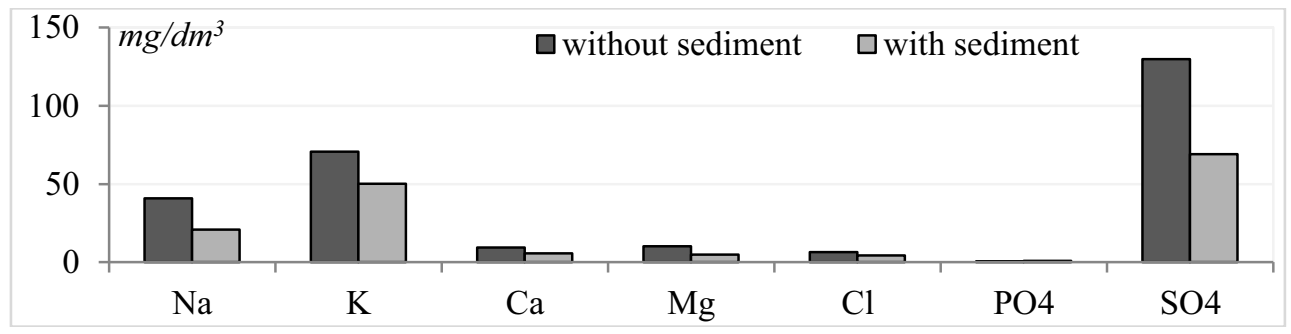

Fig. 6. Comparative diagram of the quantitative content of the cationic and anionic composition of the Bitter tincture "Stark" sample with sediment (sample 42) and without (sample 41), $\mathrm{mg} / \mathrm{dm}^{3}$

Additionally, a qualitative analysis of sediments in samples 40 and 42 was carried out. As a result of the experiments, it was found that the composition of sediments was dominated by calcium and magnesium salts (up to $55 \%$ of the sediment mass on a dry matter basis).

On the other hand, the opposite results were shown by the analysis of samples of semisweet tincture "Dr. Di Chaser with Acai Berry Flavor" (samples 45,46*) and bitter tincture "Pervak homemade with horseradish" (samples 22, 23*). In the samples with a deposit, the content of the studied ions was higher than in the samples without a deposit, which is shown in Fig. 7, 8.

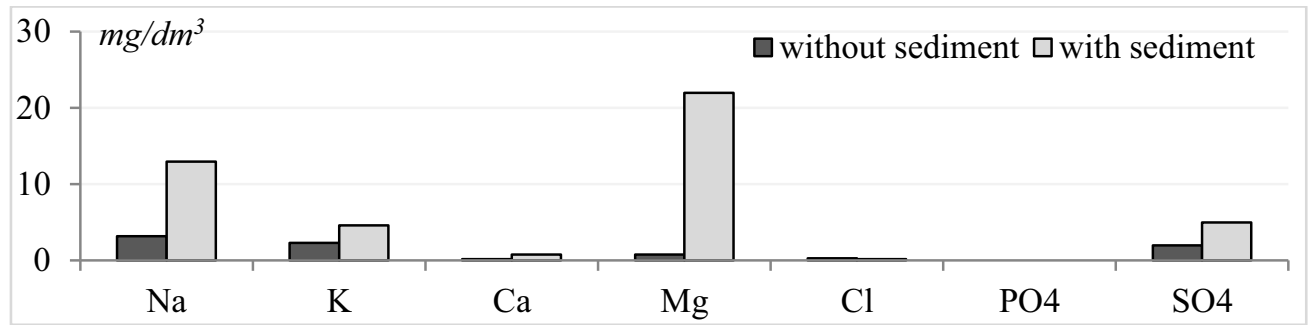

Fig. 7. Comparative diagram of the quantitative content of the cationic and anionic composition of the Semi-sweet tincture sample "Dr. Di Chaser with Acai Berry Flavor" with sediment (sample 46*) and without (sample 45), $\mathrm{mg} / \mathrm{dm}^{3}$.

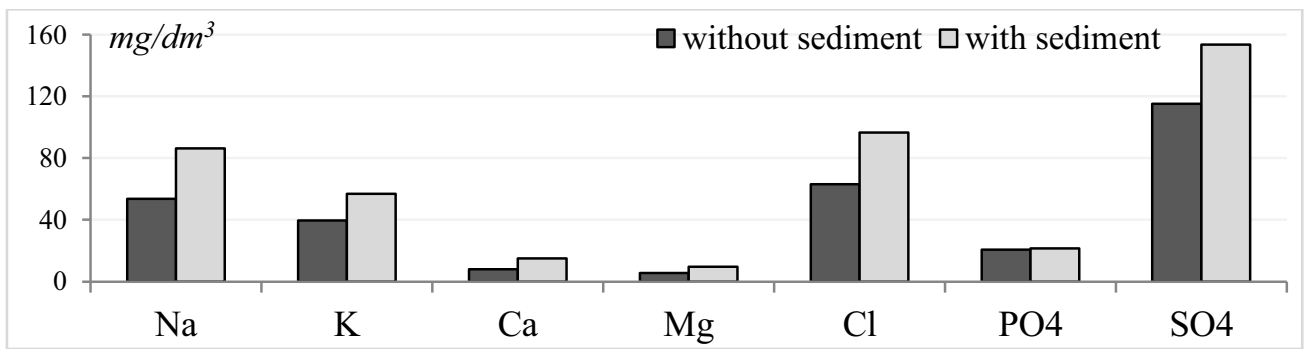

Fig. 8. Comparative diagram of the quantitative content of the cationic and anionic composition of the bitter tincture sample "Pervak homemade with horseradish" with sediment (sample 23*) and without (sample 22), $\mathrm{mg} / \mathrm{dm}^{3}$.

The $\mathrm{pH}$ of both samples with sediment was more than 7 and was 8.5 and 9 , respectively.

Additionally, the water resistance of the bottles was assessed. It was found that samples of bottles from semi-sweet tincture "Dr. Di Chaser with Acai Berry Flavor" with sediment and bitter tincture "Pervak homemade with horseradish" with sediment in terms of quality does not meet the requirements of regulatory technical documentation (GOST 32131-2013).

Based on the foregoing, we can assume that one of the reasons sedimentation in these cases was a violation of the inner surface of the bottle due to alkaline $\mathrm{pH}$. 
In some samples with and without sediment, the ionic composition did not have statistically significant differences (Fig. 9, 10).

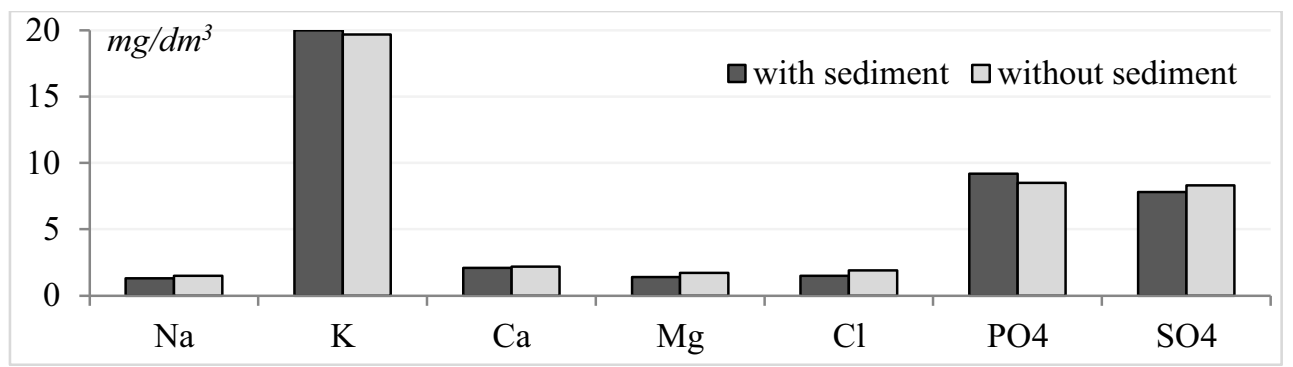

Fig. 9. Comparative diagram of the quantitative content of the cationic and anionic composition of the Semi-sweet tincture "Parliament Orange Bitter" sample with sediment (sample 38*) and without (sample 37), $\mathrm{mg} / \mathrm{dm}^{3}$.

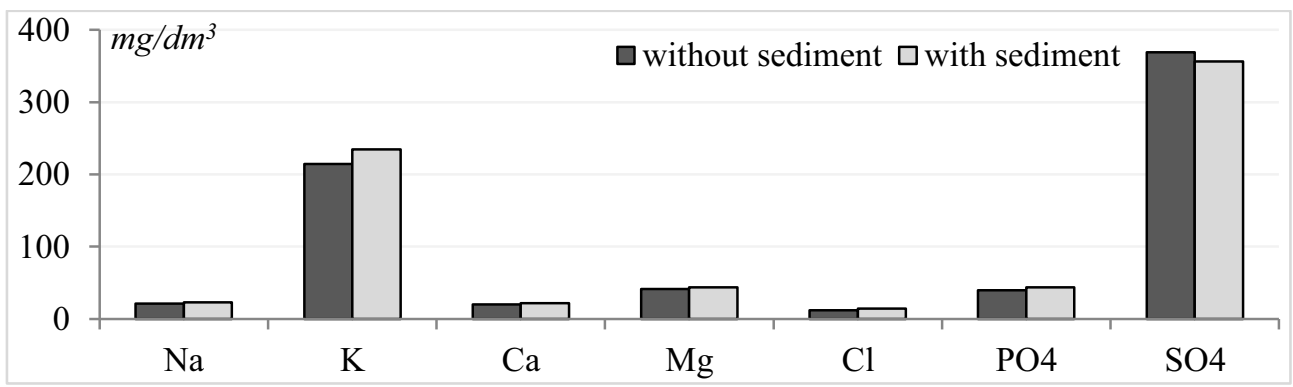

Fig. 10. Comparative diagram of the quantitative content of the cationic and anionic composition of the Sweet tincture "Batkova Cherry on cognac" sample with sediment (sample 44*) and without sediment (sample 43), $\mathrm{mg} / \mathrm{dm}^{3}$.

In these cases, the nature of the precipitate is not associated with a change in the ionic composition.

Additionally, studies were carried out [21] as a result of which, it was revealed that sedimentation in these cases is caused by protein substances. Amino acids form insoluble complexes from high molecular weight substances. This process can be catalyzed by salts of phosphates and sulfates, which are present in significant quantities in alcoholic beverages bases of distillery production - fruit infusions and juices.

\section{Conclusions}

The method of ion chromatography is an indispensable analytical tool for quality control and authenticity of liqueurs and spirits, technological and production processes of their manufacture. Its use makes it possible to timely identify and eliminate the causes of deterioration in the quality of liqueurs and spirits during storage, thereby increasing the efficiency of the technochemical quality of alcoholic beverages.

\section{References}

1. S. Morozova, V. Burachevskaya, E. Ustinova, Beer and Drinks, 1, 12-15 (2015)

2. W. Biel, A. Jaroszewska, S. Agricola, 74(5), 405-410 (2017) doi:10.1590/1678-992x2016-0314 
3. I. Abramova, V. Polyakov, M. Medrish, S. Pavlenko, Production of alcohol and alcoholic beverages, 2, 20-21 (2013)

4. N. Romanova, D. Khrundin, N. Simonova, D. Sharafutdinova, Bulletin of the Technological University, 11, 297-299 (2010)

5. N. Ageeva, L. Chemisova, M. Markovsky, Fruit growing and viticulture of the South of Russia, 30(06), 1-16 (2014)

6. J. Gómez, M. L. A. Gil, N. de la Rosa-Fox, M. Alguacil, Food Chemistry, 170, 84-89 (2015) doi:10.1016/j.foodchem.2014.08.028

7. I. Abramova, S. Morozova, V. Polyakov, N. Shubina, Beer and drinks, 6, 40-44 (2016)

8. H. Daraeia, A. Malekia, A. H. Mahvib, L. Alaeic, R. Rezaeea, E. Ghahremania, N. Mirzaeia, Journal of Water Chemistry and Technology, 37(5), 253-257 (2015) doi:10.3103/S1063455X15050082

9. A. Uzhel, A. Zatirakha, A. Smolenkov, O. Shpigun, Journal of Chromatography A, 1567, 130-135 (2018) doi:10.1016/j.chroma.2018.06.065

10. F. L. Chiriac, T. Galaon, L. Cruceru, Proceedings Book SIMI 2016, 147-155 (2016) doi: 10.21698 / simi.2016.0018

11. G. A. Zachariadis, A. I. Lyratzi, J. A. Stratis, Cent. Eur. J. Chem., 9(5), 941-947 (2011)

12. D. H. Dawood, M. I. Sanad, J. Agric, Chem. and Biotechn., 5(9), 215-226 (2014) doi:10.21608/jacb.2014.49898

13. M. Balcerzak, D. Kapica, Food Analytical Methods, 10, 2358-2364 (2017) doi:10.1007/s12161-017-0812-7

14. R. Bartzatt, B. Thompson, J. McNelly, ACAIJ, 9(4), 449-454 (2010)

15. V. Polyakov, I. Abramova, S. Morozova, M. Medrish, E. Ustinova, Production of alcohol and alcoholic beverages, 1, 20-22 (2015).

16. A. J. Johnson, H. Heymann, S. E. Ebeler, Food Chemistry, 179, 343-354 (2015) doi:10.1016/j.foodchem.2015.01.114

17. K. Kyeremeh, F. W. Agbemafo, R. Appiah-Opong, International Journal of Chemistry and Applications, 5(2), 153-167 (2013).

18. J. Polak, M. Bartoszek, R. Bernat, Scientific Reports, 9:6148, 1-9 (2019) doi:10.1038/s41598-019-42656-2

19. K. Szentmihályi, I. S. Varga, A. Gergely, M. Rábai, M. Then, Acta Biologica Hungarica, 66(3), 293-303 (2015) doi:10.1556/018.66.2015.3.5

20. A. Arceusz, M. Wesolowski, I. Radecka, Central European Journal of Chemistry, 9(5), 917-924 (2011) doi:10.2478/s11532-011-0083-x

21. N. Golovacheva, I. Abramova, S. Morozova, L. Gallyamova, Food Industry, 4, 34-38 (2020) doi:10.24411/0235-2486-2020-10041 